NBER WORKING PAPER SERIES

\title{
SURPLUS-DEBT REGRESSIONS
}

Eric M. Leeper

Bing Li

Working Paper 22662

http://www.nber.org/papers/w22662

\author{
NATIONAL BUREAU OF ECONOMIC RESEARCH \\ 1050 Massachusetts Avenue \\ Cambridge, MA 02138 \\ September 2016
}

We thank Nora Traum and Todd Walker for comments. This project is supported by National Natural Science Foundation of China (No. 71103103) and Tsinghua University Initiative Scientific Research Program (No. 20151080392). The views expressed herein are those of the authors and do not necessarily reflect the views of the National Bureau of Economic Research.

NBER working papers are circulated for discussion and comment purposes. They have not been peer-reviewed or been subject to the review by the NBER Board of Directors that accompanies official NBER publications.

(C) 2016 by Eric M. Leeper and Bing Li. All rights reserved. Short sections of text, not to exceed two paragraphs, may be quoted without explicit permission provided that full credit, including (C) notice, is given to the source. 
Surplus-Debt Regressions

Eric M. Leeper and Bing Li

NBER Working Paper No. 22662

September 2016

JEL No. C13,E62,E63,H62,H63

\section{ABSTRACT}

Single-equation estimates of fiscal reaction functions, which relate primary surpluses to past debt-GDP ratios and control variables, are subject to potentially serious simultaneity bias that can produce misleading inferences about fiscal behavior. Biases arise from failure to model the general equilibrium relationships between government debt and surpluses, relationships that bring in the forward-looking nature of nominal debt valuation and the role of monetary policy in that valuation.

Eric M. Leeper

Department of Economics

Indiana University

105 Wylie Hall

Bloomington, IN 47405

and Center for Applied Economics and Policy Research

and also NBER

eleeper@indiana.edu

\section{Bing Li}

School of Economics and Management

525 Weilun Building

Tsinghua University

Beijing, China

libing@sem.tsinghua.edu.cn 


\title{
Surplus-Debt Regressions*
}

\author{
Eric M. Leeper ${ }^{\dagger} \quad$ Bing $\mathrm{Li}^{\ddagger}$
}

\section{INTRODUCTION}

Elevated government debt levels worldwide and recent sovereign debt troubles in the Euro Area have increased interest in estimates of fiscal rules to shed light on the sustainability of fiscal policies. Many studies follow Bohn (1998) to regress the primary surplus-GDP ratio, $s_{t}$, against the lagged debt-GDP ratio, $b_{t-1}$, and a set of controls, $X_{t}$

$$
s_{t}=\gamma b_{t-1}+\mu_{t}
$$

where $\mu_{t} \equiv \Gamma X_{t}+\varepsilon_{t}^{S}$ and $\varepsilon_{t}^{S}$ is the fiscal policy shock. Bohn (1998, p. 949) interprets significantly positive estimates of $\gamma$ as evidence that "the government is taking actionsreducing noninterest outlays or raising revenue - that counteract the changes in debt." Those fiscal actions, Bohn argues, imply that fiscal policy is sustainable.

Regressions like (1) play a key role in policy analyses. They underlie the IMF's calculations of "fiscal space" [Mendoza and Ostry (2008), Ghosh, Kim, Mendoza, Ostry, and Qureshi (2012), and Mauro, Romeu, Binder, and Zaman (2015)] and a large literature that aims to test for fiscal sustainability [see D'Erasmo, Mendoza, and Zhang (2016) for an overview]. Those studies refine Bohn's criterion by requiring that $\gamma$ exceed the real-interest rate-economic growth rate differential to ensure that the debt-GDP ratio stabilizes in the long run. Because estimates of $\gamma$ lie at the heart of important policy decisions, it is essential to explore the conditions under which the regressions that (1) describes are likely to recover accurate estimates of this critical parameter.

This note does not dispute the theoretical claim that if fiscal policy obeys (1) with $\gamma$ larger than the interest rate-growth rate differential, then fiscal policy is sustainable. Instead, we question whether single-equation regressions of equilibrium surpluses on debt can reliably recover fiscal policy behavior.

\footnotetext{
*September 13, 2016. We thank Nora Traum and Todd Walker for comments. This project is supported by National Natural Science Foundation of China (No. 71103103) and Tsinghua University Initiative Scientific Research Program (No. 20151080392).

†'Indiana University and NBER; eleeper@indiana.edu.

†Tsinghua University; libing@sem.tsinghua.edu.cn.
} 
For (1) to be a regression, $b_{t-1}$ must be predetermined. That is, $E\left[\varepsilon_{t}^{S} \mid b_{t-1}\right]=0$. The economic content of this orthogonality condition is that shocks at $t-1$ that affect $b_{t-1}$ must not predict $\varepsilon_{t}^{S}$ and that the real value of debt at $t-1$ (or the debt-GDP ratio) cannot depend on the expectation of $\varepsilon_{t}^{S}$. This note scrutinizes these requirements.

Scrutiny begins by recognizing that policy rule (1) is just one of many equations that determine equilibrium sequences of surpluses and real government debt. ${ }^{1}$ Three features of any equilibrium can be important for estimates of $\gamma$ :

(i) Asset-pricing relations that determine government bond yields.

(ii) Monetary policy behavior, which affects the aggregate price level and the relationship between inflation and nominal bond returns.

(iii) The debt valuation equation, a forward-looking equilibrium condition that equates the value of government debt to the expected discounted value of primary surpluses.

The third feature, which embeds the first and optimizing private behavior, implies that

$$
b_{t-1}=E_{t-1} \sum_{T=t}^{\infty} q_{t-1, T} s_{T}
$$

where $q_{t-1, T}$ is the stochastic discount factor between periods $t-1$ and $T$ and $E_{t-1}$ denotes the expectation conditional on date $t-1$ information. This expression implies that in any equilibrium real debt tends to be positively correlated with future surpluses. Viewed in conjunction with the policy rule, (2) raises the possibility that $b_{t-1}$ is not a predetermined regressor in regression (1), as it will be correlated with the policy disturbance $\varepsilon_{t}^{S}$ when that disturbance is serially correlated.

The second feature, monetary policy, comes into play once one acknowledges that the vast majority of debt that governments issue is nominal, denominated in the country's home currency. Nominal debt is a claim to currency in the future. Governments make a policy choice about whether to pay the claim in goods (primary surpluses) or currency ("paper money" in Sims's (2013) terminology). Because $b_{t-1} \equiv B_{t-1} / P_{t-1}$, where $B$ is nominal debt, if the price level at $t-1$ depends in any way on expected future surpluses, then an additional channel exists to stabilize real debt that can undermine the maintained predeterminedness assumption that underlies treating (1) as a regression.

This note uses a simple model to illustrate the nature of potential simultaneity biases in surplus-debt regressions. Bias depends on the joint monetary-fiscal regime that determines the equilibrium price level. Bias problems are negligible when the monetary-fiscal mix implies the price level is unrelated to budget surpluses, an implication of the Ricardian nature of this equilibrium. In regimes where the price level is a function of expected surpluses, the bias is ubiquitous and may be positive or negative, depending on monetary policy behavior and the persistence of the fiscal shock. When monetary policy follows an interest-rate rule that reacts weakly to inflation - which Clarida, Galí, and Gertler (2000) document was true in the United States before 1980 and as it has in most countries since 2009- the bias is positive

\footnotetext{
${ }^{1}$ For the purposes of this note, we need not distinguish between levels and ratios of variables. We also need not examine the determinants of the control variables. For actual estimation, both of these are important.
} 
and can be quite large: estimates of $\gamma$ can be large and positive even when surpluses have evolved independently of debt.

In sum, the model suggests that studies that rely on estimates of $\gamma$ from regressions like (1) are valid only conditional on the maintained assumption that a particular monetary-fiscal regime prevails in which $\gamma$ is positive. That maintained assumption cannot be scrutinized by single-equation analyses. Scrutiny comes only from empirical work that combines (1) with the features in (i)-(iii).

\section{An Illustrative Model and Solution}

Consider a cashless version of Leeper (1991). The real interest rate is $1 / \beta$, the representative agent's discount factor. Government purchases are zero, but the government issues nominal, one-period discount bonds, $B_{t}$, and levies lump-sum taxes, which equal primary surpluses, $s_{t}$. An infinitely-lived agent derives utility from consumption and optimally chooses consumption and bond holdings each period.

Baseline surplus-debt regressions are linear, so it is without loss of generality to examine a version of the model that is log-linearized around a deterministic steady state with zero net inflation and a surplus-debt ratio of $s / b=1-\beta$. The linearized model is summarized by the four equations

$$
\begin{array}{rlrl}
\text { Fisher relation : } & R_{t}=E_{t} \pi_{t+1} \\
\text { Monetary policy : } & R_{t}=\alpha \pi_{t}+\varepsilon_{t}^{R} \\
\text { Fiscal policy : } \quad s_{t} & =\gamma b_{t-1}+\varepsilon_{t}^{S} \\
\text { Government budget : } & b_{t-1} & =\beta b_{t}-\beta R_{t}+\pi_{t}+(1-\beta) s_{t}
\end{array}
$$

where $R_{t}$ is the one-period nominal interest rate controlled by the central bank, so its inverse is the price of government bonds, $\pi_{t} \equiv P_{t} / P_{t-1}$ is the inflation rate, and $\varepsilon_{t}^{R}$ and $\varepsilon_{t}^{S}$ are exogenous, $A R(1)$ policy disturbances with $A R$ coefficients $0 \leq \rho_{R}, \rho_{S}<1$ and innovations $\xi_{t}^{R}$ and $\xi_{t}^{S}$, which are serially and mutually uncorrelated with bounded support and variances $\sigma_{R}^{2}$ and $\sigma_{S}^{2}$. Equation (3) is the model's asset-pricing relationship, equation (4) is a simplified Taylor-type rule, equation (5) is the fiscal rule, the model analog to the rule that (1) aims to estimate, and (6) is the government's flow budget constraint.

We focus on two regions of the policy parameter space that deliver unique bounded equilibria [see Leeper (1991)]:

$$
\begin{array}{lll}
|\alpha|>1,|\gamma|>1: & \text { active monetary/passive fiscal policies } & \text { "Regime M" } \\
|\alpha|<1,|\gamma|<1: & \text { passive monetary/active fiscal policies } & \text { "Regime F" }
\end{array}
$$

\subsection{Regime M}

Equilibria in regime M are conventional monetarist/new Keynesian/Ricardian solutions. Active monetary policy makes inflation depend only on monetary policy parameters and shocks and passive fiscal policy makes debt converge gradually back to steady state following either 
kind of policy disturbance. The equilibrium is

$$
\begin{aligned}
\pi_{t} & =-\frac{1}{\alpha-\rho_{R}} \varepsilon_{t}^{R} \\
b_{t-1} & =(1-\Gamma L)^{-1}\left[\left(\frac{\beta^{-1}-\rho_{R}}{\alpha-\rho_{R}}\right) \varepsilon_{t-1}^{R}-\left(\beta^{-1}-1\right) \varepsilon_{t-1}^{S}\right] \\
s_{t} & =\gamma b_{t-1}+\varepsilon_{t}^{S}
\end{aligned}
$$

where $\Gamma \equiv \beta^{-1}-\gamma\left(\beta^{-1}-1\right)<1$ and $L$ is the lag operator.

\subsection{ReGime $\mathrm{F}$}

For this regime, we consider the case of exogenous surpluses, $\gamma=0$, which is an analytically simple case of active fiscal policy. Inflation now depends on the fiscal disturbance and the state of government debt, while monetary policy acts to stabilize the real value of debt. This equilibrium is

$$
\begin{aligned}
\pi_{t} & =b_{t-1}-\frac{1-\beta}{1-\beta \rho_{S}} \varepsilon_{t}^{S} \\
b_{t-1} & =(1-\alpha L)^{-1}\left[\varepsilon_{t-1}^{R}+\left(\frac{(1-\beta)\left(\rho_{S}-\alpha\right)}{1-\beta \rho_{S}}\right) \varepsilon_{t-1}^{S}\right] \\
s_{t} & =\varepsilon_{t}^{S}
\end{aligned}
$$

where we take $\alpha \in[0,1)$ because negative responses of the interest rate to inflation, although theoretically possible, make little economic sense.

Notice that government debt is stable in both regimes. In regime M, the fiscal choice of $\gamma$ ensures stability and determines how rapidly debt returns to steady state. In regime $\mathrm{F}$, the monetary choice of $\alpha$ does the job: as (11) reveals, $\alpha$ determines the speed of adjustment of debt toward steady state. In fact, if monetary policy were active, $\alpha>1$, debt would grow without bound.

Another important difference between regimes is the equilibrium inflation process. In regime $\mathrm{M}$, as (7)-(9) make clear, inflation is decoupled from the joint $\left(s_{t}, b_{t-1}\right)$ process, an implication of Ricardian equivalence. In regime F, although the surplus evolves autonomously, it feeds directly into inflation and $b_{t-1}$ affects $\pi_{t}$ through a breakdown of Ricardian equivalence. $^{2}$ This creates a potential dependence between $P_{t-1}$, which determines real debt, $b_{t-1}$, and expected fiscal disturbances.

\section{Surplus-Debt Regressions}

We take the model to be the data-generating process and imagine that an econometrician who is endowed with the correct form of the fiscal policy rule estimates the surplus-debt regression (1). We use the solutions for $\left\{s_{t}, b_{t-1}\right\}$ reported for the two regimes to compute the linear projection $\mathcal{P}\left[s_{t} \mid b_{t-1}\right]=\phi b_{t-1}$ that the surplus-debt regression in (1) estimates. We

\footnotetext{
${ }^{2}$ In regime $\mathrm{F}$, nominal debt expansions raise nominal wealth and nominal spending, raising the price level to ensure that in equilibrium there is no change in real wealth. Details of the transmission mechanisms in this regime appear in Leeper and Leith (2016).
} 
need not include the controls, $X_{t}$, that Bohn (1998) employs - wartime government spending and a business cycle indicator-because the model does not include these factors: if the model implies that (1) is a valid regression, then the linear projection will recover $\phi=\gamma$.

Model variables are deviations from steady state and have means of zero. This implies that the linear projection may be written as

$$
\phi=\frac{E\left(s_{t} b_{t-1}\right)}{E b_{t-1}^{2}}=\gamma+\frac{E\left(b_{t-1} \varepsilon_{t}^{S}\right)}{E b_{t-1}^{2}}=\gamma+\frac{\operatorname{cov}\left(b_{t-1}, \varepsilon_{t}^{S}\right)}{\operatorname{var}\left(b_{t-1}\right)}
$$

We use the analytical solutions for equilibrium surplus and debt processes under the two policy regimes to compute the linear projection's bias - $\operatorname{cov}\left(b_{t-1}, \varepsilon_{t}^{S}\right) / \operatorname{var}\left(b_{t-1}\right)$ - in each regime. Single-equation estimates are generally biased. Bias stems from failure to satisfy the predeterminedness requirement for lagged government debt, but the nature of the bias depends on the underlying monetary-fiscal regime.

Government debt generally depends on both policy shocks in the two regimes, so the variance of debt reflects the relative variances of the two shocks as well as the policy parameters $\alpha$ and $\gamma$. But because the shocks are mutually uncorrelated, the covariance between $\varepsilon_{t}^{S}$ and $b_{t-1}$ in the surplus-debt regression (1) depends only on the fiscal disturbance, its serial correlation, and how monetary and fiscal policies react to the macroeconomic consequences of the disturbance.

\subsection{Regime M}

Because the policy shock processes are $A R(1)$ by assumption, the solution for debt in expression (8) is an $A R(2)$ in real debt. Exploiting this permits us to compute the variance of $b_{t-1}$ easily as

$$
E\left[b_{t-1}^{2}\right]=\frac{1}{1-\Gamma^{2}}\left[\left(\frac{\beta^{-1}-\rho_{R}}{\alpha-\rho_{R}}\right)^{2}\left(\frac{1+\Gamma \rho_{R}}{1-\Gamma \rho_{R}}\right) \frac{\sigma_{R}^{2}}{1-\rho_{R}^{2}}+\left(\beta^{-1}-1\right)^{2}\left(\frac{1+\Gamma \rho_{S}}{1-\Gamma \rho_{S}}\right) \frac{\sigma_{S}^{2}}{1-\rho_{S}^{2}}\right]
$$

To derive the covariance, write out the polynomial in the lag operator in (8), multiply through by $\varepsilon_{t}^{S}$, noting that $E\left[\varepsilon_{t-j}^{S} \varepsilon_{t-i}^{R}\right]=0$ for all $i$ and $j$. Then use the $A R(1)$ specification of $\varepsilon_{t}^{S}$ and apply the fact that the innovation $\xi_{t}^{S}$ is $i . i . d$. to yield

$$
E\left[\varepsilon_{t}^{S} b_{t-1}\right]=-\frac{\left(\beta^{-1}-1\right) \rho_{S} \sigma_{S}^{2}}{\left(1-\Gamma \rho_{S}\right)\left(1-\rho_{S}^{2}\right)}
$$

Combining these gives the coefficient from the linear projection

$$
\phi=\gamma-\left(1-\Gamma^{2}\right) \frac{\frac{\rho_{S}\left(\beta^{-1}-1\right)}{1-\Gamma \rho_{S}}}{\left(\beta^{-1}-1\right)^{2}\left(\frac{1+\Gamma \rho_{S}}{1-\Gamma \rho_{S}}\right)+\left(\frac{\beta^{-1}-\rho_{R}}{\alpha-\rho_{R}}\right)^{2}\left(\frac{1+\Gamma \rho_{R}}{1-\Gamma \rho_{R}}\right) \frac{\operatorname{var}\left(\varepsilon_{t}^{R}\right)}{\operatorname{var}\left(\varepsilon_{t}^{S}\right)}}
$$

The bias disappears when the fiscal disturbance is i.i.d., but the bias is always negative when the disturbance is positively serially correlated, $0<\rho_{S}<1$. Bias is clearly increasing in the variance of the fiscal disturbance relative to the monetary shock. Less obvious is that 
the absolute value of the bias rises the more aggressively monetary policy targets inflationhigher $\alpha$-because doing so reduces the variance of real debt. Similarly, one can show that the bias rises in absolute value with a more aggressive reaction of surpluses to debt - higher $\gamma$ or lower $\Gamma$.

Equilibrium condition (2) creates a positive correlation between the real value of debt, $b_{t-1}$, and the present value of surpluses, but implies nothing about the correlation between $b_{t-1}$ and $s_{t}$. The negative bias that (13) reports arises from positive serial correlation in the surplus disturbance, a fact that is well documented by estimated models. Higher $\varepsilon_{t-1}^{S}$ reduces $b_{t-1}$ and, when it also portends a higher surplus in period $t, \operatorname{cov}\left(\varepsilon_{t}^{S}, b_{t-1}\right)<0$. Passive fiscal behavior gradually reduces surpluses with lower debt to ensure that their present value falls by an amount equal to the initial drop in $b_{t-1}$. Monetary policy plays no role in determining the sign of the bias.

\subsection{REGIME F}

Applying similar reasoning to the solutions in regime $\mathrm{F}$ yields the variance of real debt

$$
E\left[b_{t-1}^{2}\right]=\frac{1}{1-\alpha^{2}}\left[\left(\frac{1+\alpha \rho_{R}}{1-\alpha \rho_{R}}\right) \frac{\sigma_{R}^{2}}{1-\rho_{R}^{2}}+\left(\frac{(1-\beta)\left(\rho_{S}-\alpha\right)}{1-\beta \rho_{S}}\right)^{2}\left(\frac{1+\alpha \rho_{S}}{1-\alpha \rho_{S}}\right) \frac{\sigma_{S}^{2}}{1-\rho_{S}^{2}}\right]
$$

and the covariance

$$
E\left[\varepsilon_{t}^{S} b_{t-1}\right]=\frac{(1-\beta)\left(\rho_{S}-\alpha\right) \rho_{S} \sigma_{S}^{2}}{\left(1-\beta \rho_{S}\right)\left(1-\alpha \rho_{S}\right)\left(1-\rho_{S}^{2}\right)}
$$

So the linear projection recovers

$$
\phi=\gamma+\left(1-\alpha^{2}\right) \frac{\frac{\rho_{S}(1-\beta)\left(\rho_{S}-\alpha\right)}{\left(1-\beta \rho_{S}\right)\left(1-\alpha \rho_{S}\right)}}{\left(\frac{(1-\beta)\left(\rho_{S}-\alpha\right)}{1-\beta \rho_{S}}\right)^{2}\left(\frac{1+\alpha \rho_{S}}{1-\alpha \rho_{S}}\right)+\left(\frac{1+\alpha \rho_{R}}{1-\alpha \rho_{R}}\right) \frac{\operatorname{var}\left(\varepsilon_{t}^{R}\right)}{\operatorname{var}\left(\varepsilon_{t}^{S}\right)}}
$$

As in regime $\mathrm{M}$, the bias disappears when the fiscal disturbance is serially uncorrelated. In contrast to regime $\mathrm{M}$, as we shall show, the magnitude of the bias depends in important ways on the monetary policy parameter $\alpha$. As above, bias is increasing in $\operatorname{var}\left(\varepsilon_{t}^{S}\right) / \operatorname{var}\left(\varepsilon_{t}^{R}\right)$.

When the fiscal shock is positively serially correlated, the sign of the bias depends on the sign of $\rho_{S}-\alpha$, the difference between the persistence of the fiscal disturbance and the strength of monetary policy's response to inflation. To understand this, first consider the case of a pegged nominal interest rate $-\alpha=0$ - as, for example, when monetary policy is at the zero lower bound. Imagine the economy starts in steady state and is hit by a positive innovation to the surplus at time $t-1$. Substituting (11) into the solution for inflation in (10), we obtain $\pi_{t-1}=-\left[(1-\beta) /\left(1-\beta \rho_{S}\right)\right] \varepsilon_{t-1}^{S}$, while real debt is $b_{t-1}=\rho_{S}\left[(1-\beta) /\left(1-\beta \rho_{S}\right)\right] \varepsilon_{t-1}^{S}$. Because the central bank is holding fixed the nominal interest rate (and the bond price), there can be no change in expected inflation and real debt decays toward steady state at a rate determined by the serial correlation of the fiscal disturbance, $\rho_{S}$. Positive serial correlation creates a positive covariance between $b_{t-1}$ and $\varepsilon_{t}^{S}$.

Now suppose that monetary policy responds to lower inflation by reducing the nominal interest rate by $\alpha \pi_{t-1}$. Lower $R_{t-1}$ raises the price of newly-issued bonds at that date. The 
government's flow budget constraint at $t-1$ explains how this monetary reaction can induce a negative covariance between $b_{t-1}$ and $\varepsilon_{t}^{S}$

$$
\beta b_{t-1}=-(1-\alpha \beta) \pi_{t-1}-(1-\beta) \varepsilon_{t-1}^{S}
$$

where in steady state $b_{t-2}=0$ and we have replaced the nominal interest rate with the policy rule, setting the monetary shock to zero. Lower $\pi_{t-1}$ raises the first term on the right, while higher surpluses reduce the second term. The ultimate effect on the real value of new debt issuance at $t-1$ can go either way, so it is possible for $b_{t-1}$ to fall. Essentially, a larger value of $\alpha$ raises the price of bonds enough to allow a lower quantity of real bonds to satisfy the budget constraint to create the negative covariance.

Although the sign and the bias are empirical matters, estimated models generally find that $\rho_{S}>\alpha$. In a policy rule like (5), the disturbance tends to be highly serially correlated, with $\rho_{S}$ values in the neighborhood of 0.95 . And estimates of $\alpha$ in passive monetary policy episodes come in well below such values, so positive bias in regime $\mathrm{F}$ is quite likely.

\section{Numerical Exploration of Bias in Regime F}

Because the bias is always negative in regime $\mathrm{M}$ when surpluses are positively serially correlated, when the true value of $\gamma$ is greater than one linear projections will not mislead. The same cannot be said if policy behavior places the economy in regime F. If in regime $\mathrm{F} \gamma=0$ and the bias is sufficiently large and positive, linear projections will mistakenly lead to an inference that fiscal policy is passively adjusting surpluses to stabilize debt: an econometrician will make a Type I error by incorrectly rejecting the null $H_{0}: \gamma=0$.

A visual representation of the potential bias may be more illuminating than expression (14). Figures 1 and 2 plot the bias as a function of the crucial parameters $\alpha, \rho_{S}$, and $\operatorname{var}\left(\varepsilon_{t}^{R}\right) / \operatorname{var}\left(\varepsilon_{t}^{S}\right) .{ }^{3}$ Estimates of dynamic stochastic general equilibrium models with monetary and fiscal policy tend to find that $\rho_{S}>\alpha$ and $\operatorname{var}\left(\varepsilon_{t}^{R}\right)<\operatorname{var}\left(\varepsilon_{t}^{S}\right)$, with the standard deviation of fiscal shocks usually many times larger than the standard deviation of the monetary shock. ${ }^{4}$ The figures report both a three-dimension plot of the bias as a function of $\rho_{S}$ and $\alpha$ and a contour plot, which reports level curves for the bias in $\rho_{S^{-}} \alpha$ space. Figure 1 $\operatorname{sets} \operatorname{std}\left(\varepsilon_{t}^{R}\right) / \operatorname{std}\left(\varepsilon_{t}^{S}\right)=0.25$ and figure 2 sets the ratio at 0.10 .

Weak monetary policy responses to inflation (small $\alpha$ ) together with strong serial correlation in the fiscal disturbance (large $\rho_{S}$ ) can produce significant positive biases. At values of $\rho_{S}=0.95$, which are typical in empirical estimates, an econometrician would obtain estimates of $\gamma$ greater than 1 for values of $\alpha$ up to 0.35 when the standard deviation of the surplus shock is four times that of the monetary shock (figure 1). Raising the relative volatility of the two disturbances to 10 leads to estimates of $\gamma$ over 1 for values of $\alpha$ up to about 0.75. Higher volatility of $\varepsilon_{t}^{S}$ raise both $\operatorname{cov}\left(\varepsilon_{t}^{S}, b_{t-1}\right)$ and $\operatorname{var}\left(b_{t-1}\right)$ to produce large effects on the magnitude of the bias.

\footnotetext{
${ }^{3}$ The model is calibrated to a quarterly frequency so $\beta=0.99$ and sets $\rho_{R}=0.7$, but results are not very sensitive to the serial correlation of the monetary disturbance. To hold $\operatorname{var}\left(\varepsilon_{t}^{S}\right)$ fixed while $\rho_{S}$ changes, the calculations vary the variance of the innovation $\xi_{t}^{S}, \sigma_{S}^{2}$, as needed.

${ }^{4}$ Papers that estimate fixed policy regimes include Traum and Yang (2011), Tan (2014), Zubairy (2014), Leeper, Traum, and Walker (2015), and Bhattarai, Lee, and Park (2016); those with Markov-switching regimes include Davig and Leeper (2006), Bianchi (2012), and Bianchi and Ilut (2014).
} 

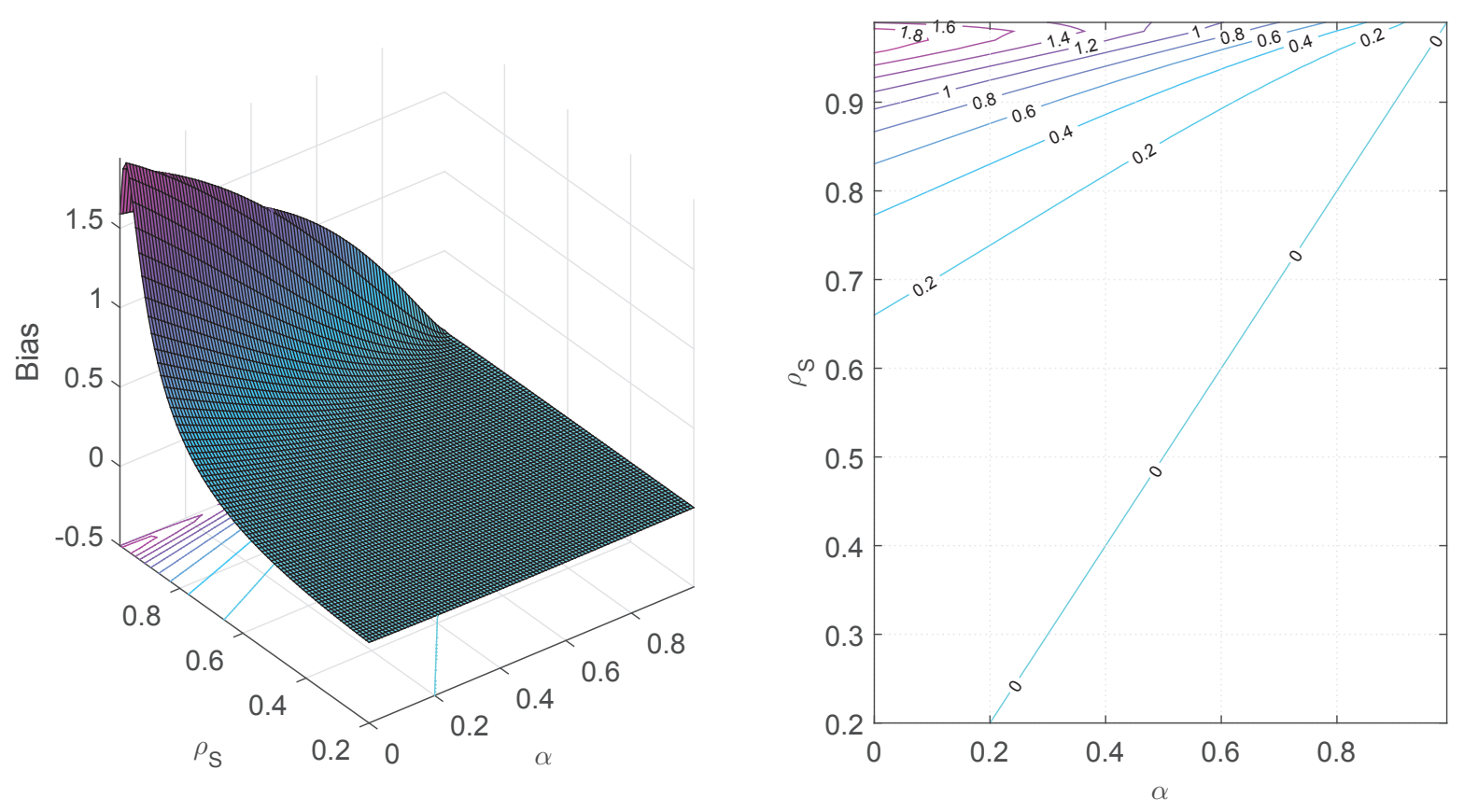

Figure 1: Regime $\mathrm{F}$ bias as a function of serial correlation of fiscal shock $\left(\rho_{S}\right)$ and monetary policy response to inflation $(\alpha)$. Figure on right depicts contours for the bias. Standard deviation of surplus shock is 4 times that of monetary shock; $\gamma=0$.

\section{Discussion}

This note's analysis finds that surplus-debt regressions are likely to yield qualitatively accurate inferences in the case when there is actually no need to be concerned about whether fiscal policy responds to stabilize debt - in regime M. Unfortunately, inferences may be seriously misleading in precisely those circumstances when actual responses of surpluses to debt are weak or non-existent-in regime F.

Although the model in this note is too simple to make plausible quantitative predictions, it serves to highlight an economic mechanism that can create bias in surplus-debt regressions. First generation estimated DSGE models like Christiano, Eichenbaum, and Evans (2005) and Smets and Wouters (2007) built in Ricardian equivalence, just as in our model's regime M. The current generation of models breaks down Ricardian equivalence in a wide variety of ways: finitely-lived agents [Annicchiarico, Giammarioli, and Piergallini (2012)], liquidityconstrained consumers [Coenen, Straub, and Trabandt (2013)], distorting taxes [Traum and Yang (2011)], financial intermediation that relies on government bonds [Villa (2013), Gelain and Ilbas (2014)], and heterogeneous agents [Kaplan, Moll, and Violante (2015)]. Each of these enrichments can make the price level depend on future surpluses to introduce the biases that appear in regime $\mathrm{F}$ of the simple model. Quantitative assessments of bias in surplus-debt regressions call for richer models like these that have been fit to data.

A thorough answer to the question of whether economies have actually resided in regime $\mathrm{F}$ is well beyond the scope of this note. But there is plenty of suggestive evidence that monetary policy has been passive $-0 \leq \alpha<1$. Clarida, Galí, and Gertler (2000) and many other studies document that for the 20 years before Paul Volcker became chair of the Fed, 

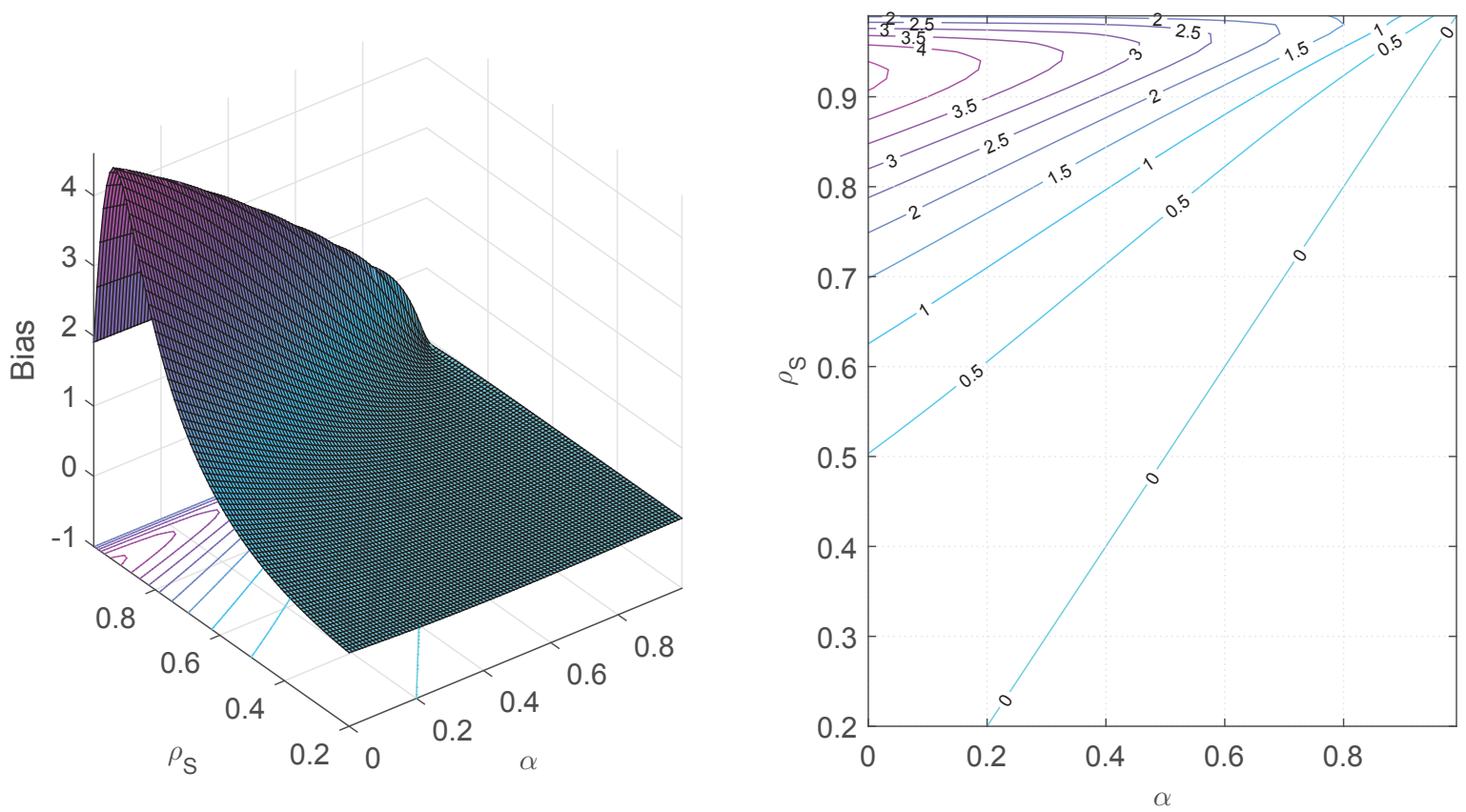

Figure 2: Regime $\mathrm{F}$ bias as a function of serial correlation of fiscal shock $\left(\rho_{S}\right)$ and monetary policy response to inflation $(\alpha)$. Figure on right depicts contours for the bias. Standard deviation of surplus shock is 10 times that of monetary shock; $\gamma=0$.

$\alpha$ was well below unity in the United States. And for over seven years since the financial crisis, policy rates in many countries have been at or near their lower bounds. The Bank of Japan has pegged overnight call rate for nearly 20 consecutive years. Similar findings emerge from Markov-switching estimates of Federal Reserve behavior [see footnote 4]. There is little doubt that monetary policy behaves passively, sometimes for extended periods.

There are fewer studies of fiscal regime. But recent estimates find that at times fiscal policy has behaved actively, as regime F prescribes. Several papers find that fiscal behavior in the United States fluctuates between passive and active episodes and other work concludes that regimes $\mathrm{M}$ and $\mathrm{F}$ fit U.S. data equally well, making it difficult to dismiss regime $\mathrm{F}$ as a plausible explanation of data [see footnote 4].

This note scrutinizes surplus-debt regressions that are used to test for fiscal sustainability. The analysis quickly evolved to examine how monetary and fiscal policies jointly determine the price level and stabilize debt. This evolution is natural when we recognize that most countries issue nominal government bonds - often the vast majority of debt-whose real value or, equivalently, whose debt-GDP ratio, depends on the aggregate price level.

Studies of fiscal sustainability rarely distinguish between real-inflation-indexed, foreign currency denominated - debt and nominal debt. Implicitly, those studies assume economies reside permanently in regime $\mathrm{M}$ so that any expansion in debt must be backed wholly by higher subsequent surpluses to assure sustainability. By not considering regime $\mathrm{F}$, that work has not brought into the analysis the roles that monetary policy and price-level adjustments may play in stabilizing the real value of government debt. As this note illustrates, surplusdebt regressions cannot control for those monetary factors. 
Recognizing that different mechanisms can stabilize real and nominal debt raises concerns about empirical findings based on long time series [Bohn (1998), Mauro, Romeu, Binder, and Zaman (2015), and D'Erasmo, Mendoza, and Zhang (2016)]. Until 1933, the United States operated under commodity money standards. Although U.S. treasuries were denominated in "dollars," because those dollars were convertible to precious metal, the government required real resources to back treasuries: debt was effectively real. After leaving the gold standard, debt obligations were payable in paper money: debt has been nominal. Regime $\mathrm{M}$ treats debt as real; regime $\mathrm{F}$ treats it as nominal. The two kinds of debt call for different analyses of fiscal sustainability.

If single-equation regressions cannot reliably recover fiscal rules, what can? Even the simple theory in this note points toward the need to integrate features (i)-(iii) in the introduction to identify and estimate fiscal behavior. Those features imply cross-equation restrictions that affect estimates of $\gamma$. Fully specified DSGE models can impose those restrictions, but whether they generally obtain accurate estimates of fiscal behavior has not been studied. Identified vector autoregressions can, in principle, also impose cross-equation restrictions [Del Negro and Schorfheide (2004)]; their ability to recover policy behavior also remains unexplored.

Estimating policy behavior requires identifying assumptions. Regressions of equilibrium surpluses and debt recover actual policy behavior only under very strong restrictions. Whether those restrictions hold in general calls for more detailed analyses. 


\section{REFERENCES}

Annicchiarico, B., N. Giammarioli, and A. Piergallini (2012): "Budgetary Policies in a DSGE Model with Finite Horizons," Research in Economics, 66(2), 111-130.

Bhattarai, S., J. W. Lee, and W. Y. Park (2016): "Policy Regimes, Policy Shifts, and U.S. Business Cycles," forthcoming in Review of Economics and Statistics.

Bianchi, F. (2012): "Evolving Monetary/Fiscal Policy Mix in the United States," American Economic Review Papers 6 Proceedings, 101(3), 167-172.

Bianchi, F., And C. Ilut (2014): "Monetary/Fiscal Policy Mix and Agents' Beliefs," Manuscript, Duke University, May.

Bohn, H. (1998): "The Behavior of U.S. Public Debt and Deficits," Quarterly Journal of Economics, 113(3), 949-963.

Christiano, L. J., M. Eichenbaum, and C. L. Evans (2005): "Nominal Rigidities and the Dynamic Effects of a Shock to Monetary Policy," Journal of Political Economy, $113(1), 1-45$.

Clarida, R., J. Galí, and M. Gertler (2000): "Monetary Policy Rules and Macroeconomic Stability: Evidence and Some Theory," Quarterly Journal of Economics, 115(1), $147-180$.

Coenen, G., R. Straub, and M. Trabandt (2013): "Gauging the Effects of Fiscal Stimulus Packages in the Euro Area," Journal of Economic Dynamics 8 Control, 37(2), $367-386$.

Davig, T., And E. M. Leeper (2006): "Fluctuating Macro Policies and the Fiscal Theory," in NBER Macroeconomics Annual 2006, ed. by D. Acemoglu, K. Rogoff, and M. Woodford, vol. 21, pp. 247-298. MIT Press, Cambridge.

Del Negro, M., and F. Schorfheide (2004): "Priors from General Equilibrium Models for VARs," International Economic Review, 45(2), 643-673.

D'Erasmo, P., E. G. Mendoza, and J. Zhang (2016): "What is a Sustainable Public Debt?," in forthcoming in Handbook of Macroeconomics, ed. by J. B. Taylor, and H. Uhlig, vol. 2. Elsevier Press, Amsterdam.

Gelain, P., And P. Ilbas (2014): "Monetary and Macroprudential Policies in an Estimated Model with Financial Intermediation," National Bank of Belgium Working Paper No. 258, May.

Ghosh, A., J. I. Kim, E. G. MendozA, J. D. Ostry, and M. S. Qureshi (2012): "Fiscal Fatigue, Fiscal Space and Debt Sustainability in Advanced Economies," The Economic Journal, 123(566), F4-F30.

Kaplan, G., B. Moll, and G. L. Violante (2015): "Monetary Policy According to HANK," Manuscript, Princeton University, November. 
Leeper, E. M. (1991): “Equilibria Under 'Active' and 'Passive' Monetary and Fiscal Policies," Journal of Monetary Economics, 27(1), 129-147.

LeEper, E. M., And C. Leith (2016): "Understanding Inflation as a Joint Monetary-Fiscal Phenomenon," in forthcoming in Handbook of Macroeconomics, ed. by J. B. Taylor, and H. Uhlig, vol. 2. Elsevier Press, Amsterdam, NBER Working Paper No. 21867, January.

Leeper, E. M., N. Traum, and T. B. Walker (2015): "Clearing Up the Fiscal Multiplier Morass," NBER Working Paper No. 21433, July.

Mauro, P., R. Romeu, A. Binder, and A. Zaman (2015): "A Modern History of Fiscal Prudence and Profligacy," Journal of Monetary Economics, 76(November), 55-70.

Mendoza, E. G., and J. D. Ostry (2008): "International Evidence on Fiscal Solvency: Is Fiscal Policy 'Responsible'?," Journal of Monetary Economics, 55(6), 1081-1093.

Sims, C. A. (2013): "Paper Money," American Economic Review, 103(2), 563-584.

Smets, F., And R. Wouters (2007): "Shocks and Frictions in US Business Cycles: A Bayesian DSGE Approach," American Economic Review, 97(3), 586-606.

TAN, F. (2014): "Two Econometric Interpretations of U.S. Fiscal and Monetary Policy Interactions," Manuscript, Indiana University, November.

Traum, N., And S.-C. S. Yang (2011): "Monetary and Fiscal Policy Interactions in the Post-War U.S.," European Economic Review, 55(1), 140-164.

Villa, S. (2013): "Financial Frictions in the Euro Area: A Bayesian Assessment," ECB Working Paper No. 1521, March.

Zubairy, S. (2014): "On Fiscal Multipliers: Estimates from a Medium-Scale DSGE Model," International Economic Review, 55(1), 169-195. 